\title{
Theoretical study of dimethylcarbonate production by urea alcoholysis
}

\author{
(C) Nikita I. Kurshev, Ksenia S. Dashkevich, Valentina Ya. Khrizanforova, \\ Alexander Ya. Samuilov, and Yakov D. Samuilov** \\ Kazan National Research Technological University. K. Marx St., 68. Kazan, 420015. \\ Tatarstan Republic.Russia.Email: ysamuilov@yandex.ru
}

*Supervising author; ${ }^{+}$Corresponding author
Keywords: dimethyl carbonate, alcoholysis, catalysis, mechanism, urea.

Abstract

Using the density functional method M06, the mechanisms of non-catalytic reactions of transesterification of urea with methanol with the formation of dimethyl carbonate, as well as in catalysis with zinc oxide and acetate, were studied. The transesterification proceeds stepwise with the intermediate formation of methyl carbamate.

The non-catalytic process of transesterification of urea with methanol proceeds by the mechanism of nucleophilic $\mathrm{S}_{\mathrm{N}} 2$ substitution and is accompanied by the formation of pre-reaction complexes, which through synchronous transition states turn into post-reaction complexes, decomposing into ammonia and methyl carbamate in the first stage and dimethyl carbonate in the second. It has been established that methanol associates can take part in these reactions. Their participation is preferable both kinetically and thermodynamically. An analysis of the equilibrium constants of the reaction of urea with methanol at various temperatures showed that in a wide temperature range their values remain large in the first stage - the formation of methyl carbamate and become significantly reversible in the second - the conversion of methyl carbamate to dimethyl carbonate.

Reactions involving acetate and zinc oxide proceed through the same stages as non-catalytic interactions. In the case of zinc acetate catalyzed reactions, if methanol monomer is involved in the reaction, the reaction of formation of methyl carbamate has a lower activation barrier compared to the reaction of conversion of methyl carbamate to dimethyl carbonate. If a methanol dimer is involved in the reaction, both reactions have a practically equal activation barrier. In the case of zinc oxide catalyzed interactions, reactions involving a methanol dimer were not detected.

The participation of the catalyst leads to a significant decrease in activation barriers, and a more significant decrease occurs in the case of catalysis with zinc oxide. The reason for the different catalytic activity, in our opinion, is the difference in the charges on the urea carbon atom in the pre-reaction complexes.

\section{References}

[1] F. Aricò, P. Tundo. Dimethyl carbonate: a modern green reagent and solvent. Russ. Chem. Rev. 2010. Vol.79. No.6. P.479-489.

[2] G.Z. Żukowska, M. Marcinek, S. Drzewiecki, J. Kryczka, J. Syzdek, A. Adamczyk-Woźniak, W. Wieczorek, A.J. Sporzyński. Studies on the influence of tris(pentafluorophenyl)borane on the properties of ethylene carbonate, dimethyl carbonate and poly(ethylene oxide) dimethyl ether lithium trifluoromethanesulfonate electrolytes Power Sources. 2010. Vol.195. No.22. P.7506-7510.

[3] P. Tundo, L. Ross, A. J. Loris. Dimethyl Carbonate as an Ambident Electrophile. Org. Chem. 2005. Vol.70. No.6. P.2219-2224.

[4] L. Wen, C.-Y. Xinand, S.-C. Yang. The effect of adding dimethyl carbonate (DMC) and ethanol to unleaded gasoline on exhaust emission. Applied Energy. 2010. Vol.87. No.1. P.115-121.

[5] M. Pacheco, C. Marshall. Review of Dimethyl Carbonate (DMC) Manufacture and Its Characteristics as a Fuel Additive. Energy \& Fuels. 1997. Vol.11. No.1. P.2-29.

[6] M. Selva. Green approaches to highly selective processes: Reactions of dimethyl carbonate over both zeolites and base catalysts. Pure Appl. Chem. 2007. Vol.79. No.11. P.1855-1867.

[7] T. Wei, M. Wang, W. Wei, Y. Sun, B. Zhong. Synthesis of dimethyl carbonate by transesterification over $\mathrm{CaO} /$ carbon composites. Green Chem. 2003. Vol.5. No.3. P.343.

[8] U. Romano, R. Twsel, M. Maurl, P. Rebora. Synthesis of Dimethyl Carbonate from Methanol, Carbon Monoxide, and Oxygen Catalyzed by Copper compounds. Ind. Eng. Chem. Prod. Res. DeV. 1980. Vol.19. No.3. P.396-403. 
[9] H. Itoh, Y. Watanabe, K. Moric, H. Umino. Synthesis of dimethyl carbonate by vapor phase oxidative carbonylation of methanol. Green Chem. 2003. Vol.5. No.5. P.558-562.

[10] Y. Yamamoto, T. Matsuzaki, S. Tanaka, K. Nishihira, K. Ohdan, A. Nakamura, Y. Okamoto. Catalysis and characterization of $\mathrm{Pd} / \mathrm{NaY}$ for dimethyl carbonate synthesis from methyl nitrite and CO. J. Chem. Soc., Faraday Trans. 1997. Vol.93. No.20. P.3721-3727.

[11] J. Ruixia, W. Shufang, Z. Xinqiang, W. Yanji, Z. Chengfang. The effects of promoters on catalytic properties and deactivation-regeneration of the catalyst in the synthesis of dimethyl carbonate. Appl. Catal., A.: Gen. 2003. Vol.238. No.1. P.131-139.

[12] H. Wang, M. Wang, N. Zhao, W. Wei, Y. Sun. CaO-ZrO2 Solid solution: A highly stable catalyst for the synthesis of dimethyl carbonate from propylene carbonate and methanol. Catal. Lett. 2005. Vol.105. No.3-4. P.253-257.

[13] B.M. Bhanage, S. Fujita, Y. Ikushima, K. Torii, M. Arai. Synthesis of dimethyl carbonate and glycols from carbon dioxide, epoxides and methanol using heterogeneous $\mathrm{Mg}$ containing smectite catalysts effect of reaction variables on activity and selectivity performance. Green Chem. 2003. Vol.5. No.1. P.71-75.

[14] T. Wei, M. Wang, W. Wei, Y. Sun, B. Zhong. Effect of base strength and basicity on catalytic behavior of solid bases for synthesis of dimethyl carbonate from propylene carbonate and methanol. Fuel

Process. Technol. 2003. Vol.83. No.1-3. P.175-182.

[15] B.M. Bhanage, S. Fujita, Y. Ikushima, M. Arai, Transesterification of urea and ethylene glycol to ethylene carbonate as an important step for urea based dimethyl carbonate synthesis. Green Chem. 2003. Vol.5. No.4. P.429-432.

[16] P. Ball, H. Fullmann, W. Heitz. Carbonates and polycarbonates from urea and alcohol. Angew. Chem., Int. Ed. Engl. 1980. Vol.19. No.9. P.718-720.

[17] P. Ball, H. Fullmann, R. Schwalm. Synthesis of carbonates and polycarbonates by reaction of urea with hydroxyl compounds. C1 Mol. Chem. 1984. Vol. 1. P.95-108.

[18] Y. Zhao, D.G. Truhlar. The M06 suite of density functionals for main group thermochemistry, thermochemical kinetics, noncovalent interactions, excited states, and transition elements: two new functionals and systematic testing of four M06-class functionals and 12 other functionals. Theor. Chem. Acc. 2008. Vol.120. No.1-3. P.215-241.

[19] M.J. Frisch, G.W. Trucks, H.B. Schlegel, G.E. Scuseria, M.A. Robb, J.R. Cheeseman, G. Scalmani, V. Barone, B. Mennucci, G.A. Petersson, H. Nakatsuji, M. Caricato, X. Li, H.P. Hratchian, A.F. Izmaylov, J. Bloino, G. Zheng, J.L. Sonnenberg, M. Hada, M. Ehara, K. Toyota, R. Fukuda, J. Hasegawa, M. Ishida, T. Nakajima, Y. Honda, O. Kitao, H. Nakai, T. Vreven, J.A. Montgomery, Jr., J.E. Peralta, F. Ogliaro, M. Bearpark, J.J. Heyd, E. Brothers, K.N. Kudin, V.N. Staroverov, R. Kobayashi, J. Normand, K. Raghavachari, A. Rendell, J.C. Burant, S.S. Iyengar, J. Tomasi, M. Cossi, N. Rega, J.M. Millam, M. Klene, J.E. Knox, J.B. Cross, V. Bakken, C. Adamo, J. Jaramillo, R. Gomperts, R.E. Stratmann, O. Yazyev, A.J. Austin, R. Cammi, C. Pomelli, J.W. Ochterski, R.L. Martin, K. Morokuma, V.G. Zakrzewski, G.A. Voth, P. Salvador, J.J. Dannenberg, S. Dapprich, A.D. Daniels, O. Farkas, J.B. Foresman, J.V. Ortiz, J. Cioslowski, D.J. Fox, Gaussian 09, Revision A.1, Gaussian, Inc., Wallingford CT, 2009.

[20] K. Lin, X. Zhou, Y. Luo, S. Lio. The Microscopic Structure of Liquid Methanol from Raman Spectroscopy. J.Phys.Chem. 2010. Vol.114. No.10. P.3567-3673.

[21] Бушуев Ю.Г., Дубинкина Т.А. Компьютерное моделирование структур метанола и жидкого метана. Ж.физ. химии. 1996. Т.70. №9. С.1628-1632.

[22] Y.J. Shi, S. Consta, A.K. Das, B. Mallic, D. Lacey. $118 \mathrm{~nm}$ vacuum ultraviolet laser/time-of-flight mass spectroscopic study of methanol and ethanol clusters in the vapor phase. J. Chem. Phys. 2002. Vol.116. No.16. P.6990-6999.

[23] Sh.-T. Tsai, J.-Ch. Jiang, M.-F. Lin. Carbon-carbon bond cleavage in the photoionization of ethanol and propanol clusters. J. Chem. Phys. 2004. Vol.120. No.19. P.8979-8984.

[24] S. Yang, S.M. Brereton, A.M. Ellis. Electron impact ionization mass spectrometry of aliphatic alcohol cluster in helium nanodroplets. Int. J. Mass Spect. 2006. Vol.263. No.1-2. P.79-86.

[25] P. Ball, H. Fullmann, W. Heitz. Carbonates and polycarbonates from urea and Alcohol. Angew. Chem. Int. Ed. 1980. Vol.9. No.9. P.718-720.

[26] M. Wang, N. Wang Zhao, W. Wei, Y. Sun. Synthesis of dimethyl carbonate from urea and methanol over ZnO. Ind. Eng. Chem. Res. 2005. Vol.44. No.19. P.7596-7599. 